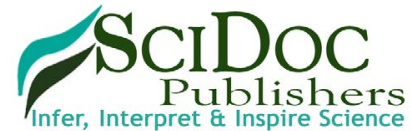

International Journal of Marine Science and Ocean Technology (IJMO)

ISSN: 2577-4395

\title{
Pinna Nobilis: An Endangered Species of Mediterranean Sea
}

Editorial

Mancuso M

Institute for Coastal Marine Environment (IAMC) - National Research Council (CNR) - Section of Messina, Italy.

\section{Abstract}

The fan mussel Pinna nobilis is the largest endemic Mediterranean bivalve that occurs in coastal and estuarine zones, living partially buried in the substrate, preferentially associated with Posidonia oceanica and Cymodocea nodosa meadows. The species in all over the world is heavily threatened and is listed and protected as an endangered species in the Mediterranean Sea. To date studies and experiments have been carried out and several are currently carrying out with the purpose to save this species, through acts of protection and through the reintroduction of the species also. In my opinion its important planning a sustainable management strategy that include an increasing of knowledge on the factors and the processes that are involved in the distribution of the species and also to trying avoid all the factors that contribute to the decrease of the population. Moreover in order to motivate and increase the consciousness and the respect for the nature it's important to spread the research and info about the environmental protection.

Keywords: Pinna Nobilis; Endangered Species; Mediterranean Sea.

\section{Introduction}

The fan mussel Pinna nobilis (L. 1758) is one of the largest bivalve mollusc in the world and is the largest endemic Mediterranean bivalve, reaching a size of up to $120 \mathrm{~cm}$ [1]. Fan mussels have a triangular shape [2] and live partially buried in the substrate [3]. They occur in coastal and estuarine zones between 0.5 and $60 \mathrm{~m}$ depth [4] preferentially associated with Posidonia oceanica and Cymodocea nodosa meadows [5]. P. nobilis is a long-lived hermaphrodite species (about 30 years).

P. nobilis population in all over the world has suffered a decline because of the heavily exploitation and for this reason the fan mussel has been listed as an endangered species (European Council Directive 92/43/EEC) in the Mediterranean Sea and has been declared a protected species (EEC 1992). To date more scientist are trying to set up a protocol for the reintroduction of the species in some habitats and the protection of the pre-existent populations, i.e. transplant could be also one of the methods useful to protect endangered species as $P$. nobilis for which first attempts of transplantation have been tried in Corsica by De Gaulejac and Vicente [6] and successively in Sicily by Bottari et al. [7]. The last research showed the feasibility and efficiency of transplanting as method to contrast $P$. nobilis population decline.

To ensure the development of sustainable management strategies it is necessary:

1. To increase the environmental conditions and population processes determine the abundance and distribution of species is a central problem of ecology and biogeography [8];

2. Try to know all the factors involved in the variation in population density and distribution;

3. To develop a common strategy to protect the environment;

4. To develop specific strategies to protect this species.

In my opinion its important planning a sustainable management strategy that include an increasing of knowledge on the factors and the processes that are involved in the distribution of the species and also to trying avoid all the factors that contribute to the decrease of the population. Moreover in order to motivate and increase the consciousness and the respect for the nature it's important to spread the research and info about the environmental protection.

\footnotetext{
*Corresponding Author:

Monique Mancuso,

Institute for Coastal Marine Environment (IAMC) - National Research Council (CNR) -Section of Messina, Spianata S. Raineri 86, 98122 Messina, Italy.

E-mail: monique.mancuso@iamc.cnr.i

Received: February 16, 2016

Published: February 22, 2016

Citation: Mancuso M (2016) Pinna Nobilis: An Endangered Species of Mediterranean Sea. Int J Marine Sci Ocean Technol. 3(1e), 1-2. doi: http://dx.doi.org/10.19070/2577-4395-160003e

Copyright: Mancuso $\mathbf{M}^{\circ}$ 2016. This is an open-access article distributed under the terms of the Creative Commons Attribution License, which permits unrestricted use, distribution and reproduction in any medium, provided the original author and source are credited.
} 


\section{References}

[1]. Zavodnik D, Hrs-Brenko M, Legac M (1991) Synopsis of the fan shell Pinna nobilis L. in the eastern Adriatic Sea. In: Les Espèces Marines à Protéger en Méditerranée. GIS Posidonie, Marseille. 169-178.

[2]. García-March JR, Márquez-Aliaga A (2007) Pinna nobilis L., 1758 age determination by integral shell register. Marine Biology 151(3): 1077-1085.

[3]. Richardson CA, Peharda M, Kennedy H, Kennedy P, Onofri V (2004) Age, growth rate and season of recruitment of Pinna nobilis (L) in the Croatian Adriatic determined from Mg: Ca and Sr: Ca shell profiles. J Exp Marine Biol Ecol 299(1): 1-16.

[4]. Butler AJ, Vicente N, De Gaulejac B (1993) Ecology of the pteroid bivalves
Pinna bicolor Gmelin and Pinna nobilis Linnaeus. Marine Life 3(1-2): 3745.

[5]. Katsanevakis S (2005) Population ecology of the endangered fan mussel Pinna nobilis in a marine lake. Endang Species Res 1: 1-9.

[6]. De Gaulejac B, Vicente N (1990) Ecologie de Pinna nobilis (L.) mollusque bivalve sur les côtes de Corse. Essais de transplantation et expériences en milieu contrôlé. Haliotis 20: 83-100.

[7]. Bottari T, Spinelli A, Busalacchi B, Rinelli P, Giacobbe S- Transplant trials of the fan mussel Pinna nobilis inside of the SCI of Capo Peloro (Central Mediterranean, Italy)- Journal of shellfish. In press.

[8]. Brown JH (1984) On the relationship between abundance and distribution of species. Am Nat 124(2): 255-279. 